\title{
Análisis diacrónico de los roles y estereotipos de género en las ilustraciones de la literatura infantil y juvenil
}

\section{Diachronic analysis of gender roles and stereotypes in illustrations of children's and young adult literature}

\section{José Vicente Salido López}

Universidad de Castilla-La Mancha josevicente.salido@uclm.es

ORCID ID: http://orcid.org/0000-0001-9165-6176

\section{Pedro V. Salido López}

Universidad de Castilla-La Mancha pedrovictorio.salido@uclm.es

ORCID ID: http://orcid.org/0000-0003-3447-5365

DOI: $10.17398 / 1988-8430.34 .15$

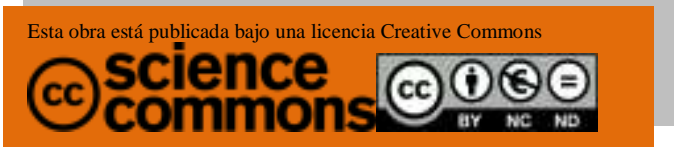

Fecha de recepción: 09/03/2021

Fecha de aceptación: 14/07/2021

OPEN $\rightarrow$ ACCESS

Salido López, J. V., y Salido López P. V. (2021). Análisis diacrónico de los roles y estereotipos de género en las ilustraciones de la literatura infantil y juvenil. Tejuelo, 34, 15-48.

Doi: https://doi.org/10.17398/1988-8430.34.15 
Resumen: El presente artículo consiste en un análisis diacrónico de la literatura infantil española de las últimas cuatro décadas. Busca el objetivo de estudiar la repercusión de los avances en el ámbito de la igualdad logrados en los últimos años. Para ello, a partir de una selección de lecturas infantiles publicadas entre 1980 y 2020, analizamos las ilustraciones que contienen atendiendo a elementos que pueden suponer la representación de estereotipos tradicionales sobre los roles sociales y caracterizaciones de hombre y mujer. El análisis demuestra la evolución que se ha experimentado en relación con la superación de determinados estereotipos que son recurrentes en obras de los primeros años de la década de los 80, en especial en las obras publicadas en la última década estudiada.

Palabras clave: literatura infantil; ilustración; estereotipo; imagen.
Abstract: This article consists of a diachronic analysis of Spanish children's literature of the last four decades. It seeks the objective of studying the impact of the advances in the field of equality achieved in recent years. To this end, based on a selection of children's readings published between 1980 and 2020, we analyze the illustrations they contain, paying attention to elements that may imply the representation of traditional stereotypes about the social roles and characterizations of men and women. The analysis shows the evolution that has been experienced in relation to overcoming certain stereotypes that are recurrent in works from the early years of the 1980 s, especially in works published in the last decade studied.

Keywords: children's literature; illustration; stereotype; image. 


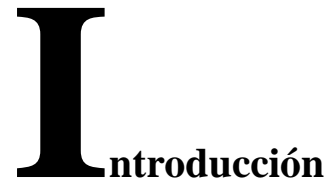

Los avances que se van logrando en el terreno de la igualdad tienen a la vez causa y efecto en el ámbito de la educación formal. La coeducación se ha convertido en un pilar fundamental dentro de cualquier currículo educativo y es el camino para seguir dando pasos en una parcela en la que aún queda mucho por hacer. Por ejemplo, sigue pendiente la superación de determinados estereotipos sexuales de origen social y transmisión cultural que, como demuestra su evolución en el tiempo, pueden ser corregidos.

En el presente trabajo buscamos precisamente analizar la repercusión de esos avances de la coeducación en la representación gráfica de hombres y mujeres dentro de la literatura infantil y juvenil. En una revisión diacrónica que abarca las cuatro últimas décadas, proponemos el estudio de las ilustraciones de algunas de las publicaciones para el público infantil más relevantes en el ámbito hispánico para observar la presencia de estereotipos de género, las 
estrategias para su representación y, cuando la hay, la mitigación o superación de los roles y caracterizaciones sexistas.

Nos centramos en la horquilla temporal entre 1980 y 2020 porque es con el desarrollo de la transición y el inicio de la democracia en el último lustro de la década de los setenta cuando se inicia una metamorfosis cultural significativa que permitie visibilizar y materializar los derechos civiles, políticos y sociales de la mujer con el avance en políticas de igualdad. En el ámbito social, es a partir del año 80 cuando se promulgan diferentes leyes que hicieron visibles políticas de igualdad efectiva de oportunidades, así como principios no discriminatorios por cuestiones de género (Lombardo y León, 2014). Desde ahí, paulatinamente esos avances sociales han ido llegando al ámbito de la ilustración de la literatura infantil y juvenil y ese análisis es precisamente el objetivo de nuestra aportación.

Obviamente, este reflejo podría rastrearse también en el componente textual, pero abordar esa doble perspectiva rebasaría con mucho los límites de este trabajo. Por ello, nos fijamos como objetivo principal de la investigación el estudio del mensaje visual desde el punto de vista de la coeduación en los peritextos. Somos conscientes de la complementariedad de ambos lenguajes (textual y visual), pero se trata de dos componentes diferentes que requieren de inicio un análisis independiente al que no podemos llegar en este momento.

En definitiva, en este estudio, a partir de la definición del concepto de estereotipo y de la revisión de la importancia de la literatura en su configuración, se plantea el análisis de un corpus de ilustraciones que forman parte de las obras publicadas entre $1980 \mathrm{y}$ 2020. Se pretende observar cómo se ha tratado la representación de los estereotipos de género y comprobar si los avances que se han hecho en las últimas décadas en el campo de la igualdad han tenido calado entre las estrategias utilizadas por los ilustradores a la hora de poner imagen a los hombres y mujeres que protagonizan la historia de cada obra analizada. 


\section{A propósito del concepto de estereotipo}

A pesar de las dificultades que supone dar con una definición más o menos precisa, y a la vez integradora, del estereotipo (FernándezMontesinos, 2016), podría entenderse de manera general como «a way of representing and judging other people in fixed, unyielding terms» (Pickering, 2007, p. 4773). Consiste en la configuración de una idea prototípica, no científica y de carácter subjetivo que permite la formación de expectativas sobre una determinada realidad, con frecuencia relacionada con referentes humanos, aunque aplicable a campos de diversa naturaleza.

Desde un punto de vista cognitivo, el estereotipo es un factor esencial en el proceso de aprendizaje porque sirve para simplificar la realidad y, en consecuencia, para aprehenderla con más facilidad (Pla, Adam y Bernabéu, 2013); también porque, entre otras funciones, colabora en la socialización del individuo al desarrollar en él una conciencia de pertenencia al grupo con el que comparte esos patrones de clasificación y caracterización (González, 1999).

No obstante, la formación de esas representaciones prefijadas también puede suponer la adquisición de prejuicios (negativos o positivos) que, por lo general, se vinculan culturalmente a la conceptualización de determinados grupos sociales (Dovidio, Evans y Tyler, 1986; García-Prieto y Arriazu-Muñoz, 2020), llegando en ocasiones a condicionar nuestro comportamiento y el de los demás (Heilman, 2001; Steele, 1997).

En este grupo de imágenes sociales pueden incluirse determinados estereotipos sexuales que equivalen a representaciones culturales sobre las características que deben poseer hombres y mujeres como grupos sexuales genéricamente diferentes y sobre sus roles dentro de la sociedad (Boch y Ferrer, 2003; de Lemus, 2007; Fiske y Stevens, 1993; Morales y López, 1993; Moya, 2003; Pla, Adam y Bernabéu, 2013; Velasco, 2009). 
Para explicar el origen de estos estereotipos, García (2005) aporta distintas teorías: la sociobiológica, la psicodinámica y el constructivismo social. La primera de ellas pretende explicar el comportamiento individual derivado de la percepción de diferencias sexuales en relación con un modelo instintivo marcado por las diferencias fisiológicas de hombres y mujeres. La segunda se relaciona con el ámbito de la psicología y vincula el origen del estereotipo con el proceso de identificación primaria del niño con el padre, en tanto que tiene su objeto de deseo en la madre, y de la niña con la madre por el planteamiento inverso. La tercera teoría se fundamenta en las diferencias de género en la educación y en el contexto social, considerando el género una construcción del lenguaje, de la historia y de la cultura.

Es decir, la formación del estereotipo de género depende de factores biológicos y psicológicos que derivan de elementos instintivos o automáticos en el desarrollo cognitivo del individuo, pero también de factores de aprendizaje que proceden de la asunción de usos y comportamientos sociales. Precisamente este componente constructivista es el que permite explicar los cambios de los roles y de los estereotipos en función de la evolución ideológica de las sociedades.

Este fenómeno de cambio ha quedado demostrado, para el caso de la cultura occidental, en diversos estudios que han analizado las modificaciones en la percepción de las características prototípicas de hombres y mujeres en función del avance de sus roles dentro de la sociedad (Castillo-Mayén y Montes-Berges, 2007 y 2014; Diekman y Eagly, 2000; Diekman, Eagly, Mladinic y Ferreira, 2005; GarcíaRetamero, Müller y López-Zafra, 2009; González, 1999; Hoffman y Hurst, 1990; Jost y Hamilton, 2005; López-Sáez, Morales y Lisbona, 2008; López-Zafra, García-Retamero, Diekman y Eagly, 2008; Moya y Pérez, 1990; Vignera, 2018). En ellos queda demostrada la capacidad que tienen las culturas para moderar y corregir determinados desvíos en los estereotipos, bien por procesos naturales, bien mediante la aplicación de mecanismos desafiantes que cuestionan y transforman los elementos de dominación que vienen impuestos por tradición (GarcíaPrieto y Arriazu-Muñoz, 2020). 
Por ello, una vez comprobada la evolución en las percepciones sociales sobre las características y roles de género en la cultura occidental, pretendemos analizar en un estudio diacrónico su reflejo en la literatura infantil. El interés por este tipo de obras radica, en primer lugar, porque son una herramienta formativa que se emplea desde las primeras etapas de desarrollo, un momento clave en la conformación de estereotipos, y, en segundo, por la importancia del componente visual en este tipo de textos, un factor esencial en la configuración de las representaciones mentales estereotipadas.

\section{La importancia de la educación: la imagen en el tratamiento de los estereotipos}

La capacidad de intervención en la estereotipia de género y, en consecuencia, la posibilidad de corregir las actitudes o comportamientos sociales que se derivan de ella han hecho que la coeducación se convierta en un componente esencial en el proceso formativo desde sus primeras etapas (Salamanca, 2014). Diversos estudios han demostrado que hacia los 3-4 años empieza a surgir la conciencia de las diferencias sexuales y, con ella, los patrones sociales sobre comportamientos, actitudes y roles de cada sexo (Aznar-Díaz y Fernández-Martín, 2004; Guil-Bozal, 1998; Unger, 1989). Así se entiende que en los últimos años hayan proliferado propuestas que abordan la coeducación en los niveles formativos básicos (Rodríguez, 2016; Tomé, 2002; Vega, 2012).

En lo que toca a la literatura, algunas de las funciones que se le suponen en esas primeras etapas educativas tienen que ver con la comprensión del mundo desde un enfoque sociocultural concreto (Cervera, 1989; Colomer, 2008; Guimarães, 2013; Schon y Berkin, 1996) y con la adquisición de una axiología dependiente también de una determinada sensibilidad social (Saneleuterio y López, 2019).

En este proceso de interiorización de lo que la sociedad considera correcto o incorrecto en el aprendizaje de normas y valores sociales los libros infantiles ofrecen numerosas posibilidades (Ros, 
2012/13), también en el ámbito de los estereotipos de género, como demuestran distintos estudios que analizan la representación de los roles sexuales en la producción literaria infantil y sus repercusiones en el comportamiento del niño (Ashton, 1978; Azevedo, Balça, Selfa y Zamith, 2015; Brugeilles, Cromer y Cromer, 2002; Hamilton, Anderson, Broaddus y Young, 2006; Masats y Creus, 2006; Martínez y Torres, 2014; Pastor, 2014; Peterson y Lach, 1990).

En el caso de las lecturas infantiles, interviene otro factor esencial en la configuración del estereotipo: el de la frecuente presencia de imágenes, un elemento que sirve de apoyo para la comprensión lectora y que es esencial en la configuración del significado y en la calidad de los libros infatiles (Martín-Macho y Neira-Piñerio, 2018), pero que influye a la vez en la representación estereotipada de la realidad. Desde la Psicología, el constructivismo demuestra cómo el niño edifica su universo a partir de su relación con los objetos (con lo que ve), siendo la imagen mental una relación que hace nuestro pensamiento entre lo que ve y lo que recuerda de ese objeto en su ausencia (Campos y González, 2017; Paivio, Rogers y Smithe, 1968). Ahí radica la relación del estereotipo con la ilustración infantil, que tradicionalmente ha colaborado en la representación prototípica de roles sexistas en la sociedad (Terrón y Cobano-Delgado, 2008; Turin, 1989, 1995, 1996 y 2002; Weitzman, Heifler, Okada y Ross, 1972) y que, en los últimos años, se esfuerza por superarlos (Cañamares-Torrijos y Moya-Guijarro, 2019; Moya-Guijarro y Cañamares-Torrijos, 2020).

\section{El análisis de la representación de estereotipos en las ilustraciones de la literatura infantil}

\subsection{Objetivos}

A partir de los estudios citados, puede concluirse que la ilustración en las obras infantiles es un elemento que recoge y transmite los estereotipos sexuales que imperan en una determinada sociedad, y, por ende, también puede ser reflejo de las modificaciones que pueden sufrir como consecuencia de los avances en el ámbito de la igualdad. 
Precisamente, ese valor de indicador de la evolución del pensamiento social es lo que motiva el presente estudio, que busca revisar con criterios diacrónicos los rasgos generales en la representación de la mujer y del hombre dentro de los libros infantiles.

De esa revisión temporal de las ilustraciones que pueden tener asociados sesgos relacionados con la estereotipia de sexo se pretenden los siguientes objetivos:

- Valorar la funcionalidad de la imagen asociada a narrativas infantiles desde el punto de vista de la coeducación.

- Analizar comparativamente la representación de estereotipos de género en las ilustraciones de la literatura infantil y juvenil española en obras publicadas entre los años 1980-2020.

- Comprobar si los avances que se han hecho en las últimas décadas en el campo de la igualdad se ven reflejados en la representación de hombres y mujeres en la literatura infantil y juvenil.

\subsection{Metodología}

El análisis de ilustraciones se aborda desde una metodología descriptiva de carácter cualitativo que estudia tres parámetros relacionados con la representación estereotipada de personajes masculinos y femeninos en la ilustración literaria: la caracterización y los atuendos con sesgos sexistas (Turin, 1995), los artefactos manejados y las acciones desarrolladas (Crabb y Bielawski, 1994; Hamilton et al., 2006) y la aportación de las localizaciones de los personajes con un valor simbólico (Cañamares-Torrijos y Moya-Guijarro, 2019).

La muestra seleccionada se compone de un total de 40 obras ilustradas publicadas en el ámbito español entre 1980-2020 ${ }^{1}$, fijando

Véase la relación de obras analizadas en el anexo que acompaña a este artículo. Tratamos como dos obras independientes las dos ediciones de Cucho, de José Luis Olaizola $(1982,2018)$, en tanto que las ilustraciones, que son nuestro objeto de análisis, pertenencen a autores diferentes (Antonio Tello y Paula Blumen) y, además, 
como criterio para su incorporación al estudio que sean obras premiadas $^{2}$. La premisa de selección de libros ilustrados premiados se impone para asegurar que son obras que representan una manera particular de entender la literatura infantil en cada momento y para garantizar la influencia en el colectivo infantil y juvenil.

Todas las obras analizadas forman parte de colecciones de literatura infantil del ámbito español. Aunque contamos con algún autor extranjero, como el boloñés Carlo Fabretti o el argentino Franco Vaccarini, su inclusión en la lista de análisis se justifica por haber sido premiados y publicados en editoriales españolas. Y el mismo criterio es el que se ha aplicado en la selección de ilustradores e ilustradoras. El objetivo de nuestro trabajo es ver el avance diacrónico en la repersentación de estereotipos en el ámbito hispánico, de ahí que hayamos desechado cualquier obra publicada fuera de ese contexto. Una visión internacional del asunto obligaría a un diseño de análisis mucho más complejo que no puede ser abordado en los límites que fijamos para este estudio.

Los títulos seleccionados en la investigación giran en torno a las edades de 7 a 11 años, pues es en esta franja donde se da con más frecuencia la presencia de imágenes que refuerzan el texto (Borda, 2006). Atendiendo a la clasificación de Cerrillo, Larrañaga y Yubero (2002), en los primeros momentos de este intervalo la imagen se

suponen una evidencia para la demostración del avance ideológico en la representación gráfica.

Aunque semióticamente existen diferencias en la interrelación entre imagen y texto en el libro ilustrado, el álbum ilustrado o el cómic (Arizpe y Styles, 2004), para nuestro fin tales diferencias en la función comunicativa no son significativas. Por ello, no incluimos como variable el género de la obra, en tanto que la representación estereotipada no depende de las interrelaciones de significado entre texto e imagen.

${ }^{2}$ Entre la selección incluimos obras ganadoras del Premio Barco de Vapor, de SM, del Premio Lazarillo de Ilustración, del Premio Nacional de Narrativa Infantil y Juvenil, del Premio Internacional del Álbum Ilustrado Edelvives y del Premio de Concurso de Narrativa Infantil Vila d'Ibi. Seleccionamos aquellas obras que cuentan con ilustraciones que responden a nuestros intereses por incluir elementos susceptibles de ser analizados en relación con la estereotipia de género. 
presenta como un refuerzo esencial del texto y con un alto porcentaje de presencia en la obra, lo que las hace ideales para nuestros intereses.

En cuanto a la distribución por año de publicación, la selección se compone de 6 obras publicadas en la década de los 80, 8 en la década de los 90, 8 en los años 00, y 18 en la última década analizada. El desfase se justifica por el aumento de signos de superación de estereotipia en los últimos años, con representaciones más variadas en los roles que requieren una selección más amplia que dé cuenta de un fenómeno que, como veremos, se materializa en diversos detalles gráficos.

\subsection{Resultados ${ }^{3}$}

\subsubsection{Caracterización de personajes en las ilustraciones de la} literatura infantil: análisis de la evolución de los estereotipos de género

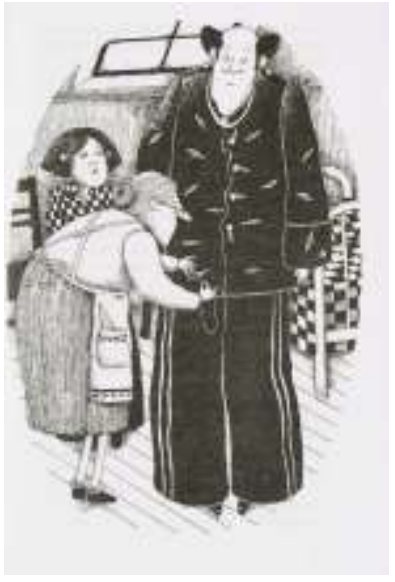

Fig. 1. Ilustración de Antonio Tello en Cucho, de José Luis Olaizola (1983)

Aunque a partir de la década de los 80 la imagen femenina experimentó una apertura bastante significativa que representó la ruptura con los cánones tradicionales, algunas ilustraciones de la literatura infantil de estos años no dejan de ser un testimonio de los prototipos masculino y femenino de los años centrales del siglo XX. Ejemplo de ello se encuentra en las representaciones que Antonio Tello realizó para Cucho, de José Luis Olaizola, en su edición de 1983 (Fig. 1), donde el hombre viste de pantalón y chaqueta y la mujer se presenta con falda y delantal, símbolo

${ }^{3}$ Las imágenes utilizadas en este artículo solo tienen finalidad docente e investigadora. No existen fines lucrativos. 
este último del rol de cuidadora del hogar asociado tradicionalmente con la mujer (Turin, 1995) ${ }^{4}$.

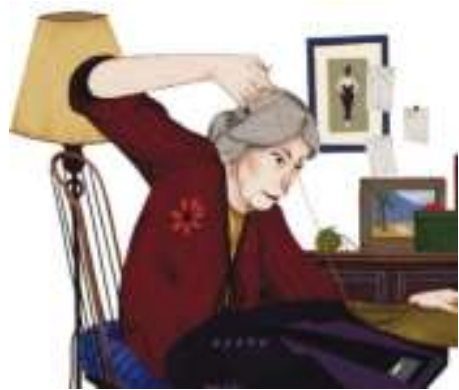

Fig. 2: Ilustración de Paula Blumen en Cucho, de José Luis Olaizola (2018)

Las mismas características para la representación del género femenino que se encuentran en la obra de Olaizola aparecen en las ilustraciones de Un duende a rayas, de María Puncel (1983). La abuela Rosalía, a la que puso imagen Margarita Puncel, se presenta ante el lector realizando tareas de costurera y con una caracterización que se convierte prácticamente en una réplica de los atuendos del dibujo de Antonio Tello en Cucho (Fig. 3).

Un solo de clarinete, de Fernando Almena (1983), libro infantil ilustrado también por Margarita Puncel, es otro ejemplo de esa perpetuación en los ochenta de los prototipos de hombre y mujer propios de las décadas centrales del siglo $\mathrm{XX}$. En este caso, la historia gira en torno a la vida de Ramón, un joven que veraneaba en Corralejo de la Sierra, el pueblo de sus abuelos. Las imágenes realizadas por Puncel presentan al abuelo con ropa clásica, con boina y bigote. Mientras, la representación de la abuela responde a las características que se han descrito en Cucho o Un duende a rayas: un delantal y

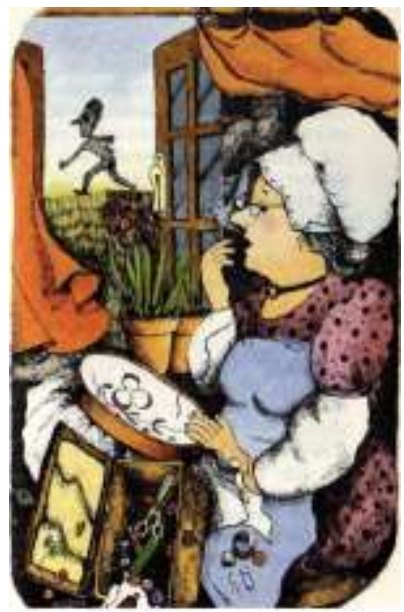

Fig. 3. Ilustración de Margarita Puncel en Un duende a rayas, de María Puncel (1983)

${ }^{4}$ En la edición de 2018, Cucho cuenta con nuevas ilustraciones realizadas por Paula Blumen. Ello permite comprobar la evolución que venimos analizando en la representación concreta de la abuela costurera. Mientras que en los años ochenta la estética era propia de una herencia de las décadas centrales del siglo XX (Fig. 1), en la edición de 2018 se tiende a una modernización del atuendo -con desaparición del delantal-y de la actitud -más erguida y estéticamente más cuidada- que evidencia la adaptación a la que se ha sometido la ilustración de los textos infantiles (Fig. 2). 
un vestido propio de la estética de una persona de mediana edad de mediados de siglo (Almena, 1983, p. 32).

Un ejemplo de esa época que parece romper la representación clásica de la mujer se encuentra en la obra Jeruso quiere ser gente, de Pilar Mateos (1981). La señora de la corbata, un personaje extraño que llega al pueblo de Jeruso, se ilustra con unos atuendos poco usuales en el colectivo femenino (Fig. 4). Pero el texto sobre el que se apoya esa representación gráfica viene a dar cuenta precisamente de que esos rasgos que no son prototípicos son entendidos como una excentricidad del personaje, lo que no deja de ser otra muestra de la misma visión clásica en la representación de la mujer que encontramos en las obras de esos años:

Era una señora muy sospechosa. No parecía una madre, ni siquiera una tía. Era tan grande como dos madres o dos tías. Tenía el pelo muy corto,

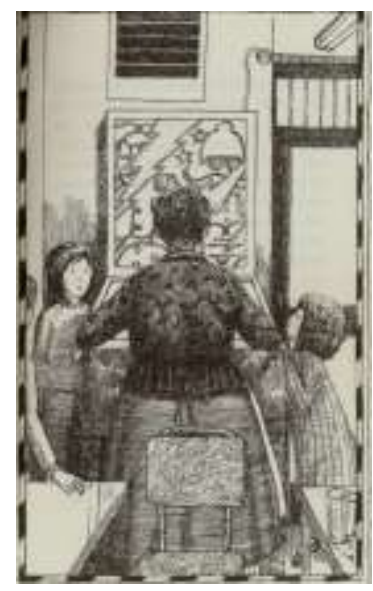

Fig. 5: Ilustración de Alfonso Ruano en Jeruso quiere ser gente, de Pilar Mateos (1981)

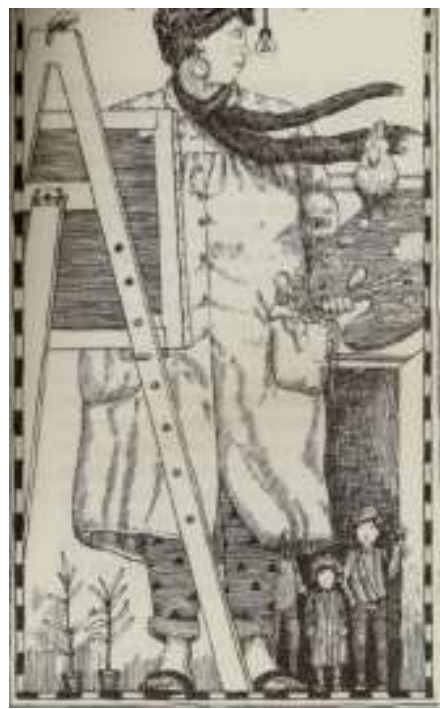

Fig. 4: Ilustración de Alfonso Ruano en Jeruso quiere ser gente, de Pilar Mateos (1981) llevara de sombrero una gran yema de huevo. Y se vestía con un mono, igual que Enrique, el del garaje. (Mateos, 1981, p. 28).

La prueba de que la ilustración en esa obra responde a los cánones tradicionales que imperaban en la época la encontramos en la representación gráfica de otros personajes femeninos no marcados por el carácter llamativamente excéntrico de la señora de la corbata, como, por ejemplo, la abuela Tomasa 
(Fig. 5), que repite el mismo patrón ya visto en Cucho o en Un duende a rayas.

Algunos avances en la superación de estos estereotipos más clásicos se pueden documentar en obras del inicio de la década de los noventa, como en Apareció en mi ventana, de Alfonso Gómez Cerdá (1990). Las ilustraciones que Jesús Gabán realizó de Sabina y Riky, la empleada del hogar de la familia de Gil y su novio, representan modelos propios de los años ochenta. Desde la perspectiva actual podrían extraerse diversas connotaciones machistas de la ilustración, pero, sin duda, esta nueva visión del hombre y de la mujer supone un avance en la ruptura de los parámetros

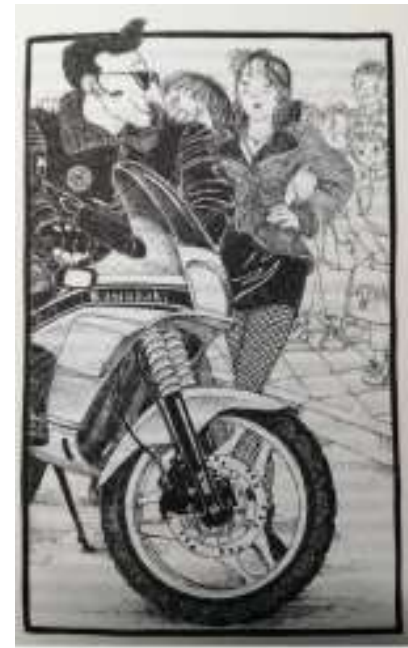

Fig. 6: Ilustración de Jesús Gabán en Apareció en mi ventana, de Alfonso Gómez Cerdá (1990) clásicos (Fig. 6).

No obstante, el cambio en este ámbito se empieza a observar con claridad en obras de los años diez de nuestro siglo. Los avances en la representación no marcada por estereotipos se demuestran en elementos como la aparición del pantalón como prenda de vestir femenina, algo muy poco frecuente en las ilustraciones de la pasada centuria, pero que empieza a ser habitual en obras como Una terrible palabra de nueve letras, de Pedro Mañas (2012), ilustrada por Ximena Maier, en Veintisiete abuelos son demasiados, de Raquel López (2014), texto ilustrado por Agustín Comotto, o en Cómo arreglar un libro mojado (2017), obra de Roberto Aliaga, con imágenes de Clara Soriano (Fig. 7). Estamos, pues, ante una muestra de la evolución en la caracterización de los personajes atendiendo al género, sobre todo en el contexto femenino.

También se materializa este avance ideológico en una tendencia hacia la neutralización de los rasgos sexuales, con el uso de atuendos no marcados que reducen a detalles mínimos las diferencias entre 
personajes masculinos y femeninos. El fenómeno puede comprobarse en obras como Mi vecino de abajo, de Daniel Nesquens. Las ilustraciones que Fran Collado dedicó al protagonista de la historia y su amigo Guillermo dan cuenta de esa tendencia hacia la neutralización en la manera de caracterizar a los personajes (Fig. 8), una técnica que puede observarse también en obras como El secreto del huevo azul, de Catalina González Villar (2012).

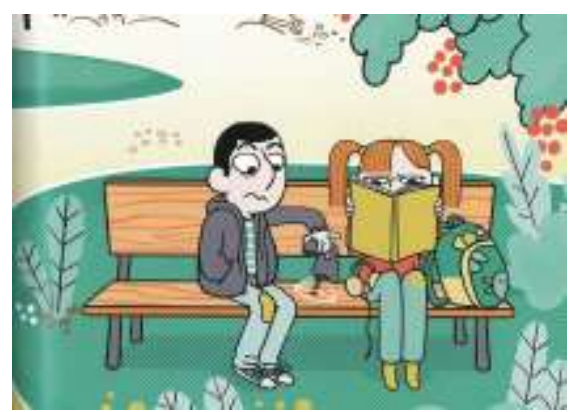

Fig. 7: Ilustración de Clara Soriano en

Cómo arreglar un libro mojado, de Roberto Aliaga (2017)

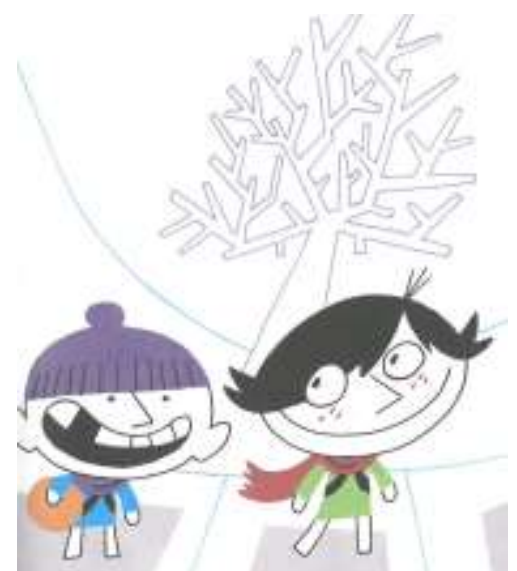

Fig. 8: Ilustración de Fran Collado en Mi vecino de abajo, de Daniel Nesquens (2011) 


\subsubsection{Artefactos y acciones en las ilustraciones de la literatura infantil: análisis de la evolución de los estereotipos de género}

Según la Asociación de Amas de Casa y Consumidores y Usuarios de la Comunidad de Madrid (AACCU), el 80\% de las mujeres de los años 70 eran amas de casa (Peraita, 2017). Como no podía ser de otra manera, esta realidad tuvo su eco en las ilustraciones de la literatura infantil, que solían representar al colectivo femenino de mediana edad vinculado a las tareas del hogar. Así, según Turin, "las madres de los libros infantiles no tienen profesión ni oficio, no hacen deporte, no muestran intereses culturales, no invitan ni son invitadas, no van al cine, no se pasean" (1995, p. 18). Prueba de la representación de este modelo de feminidad en las ilustraciones de obras infantiles son los ejemplos ya vistos de

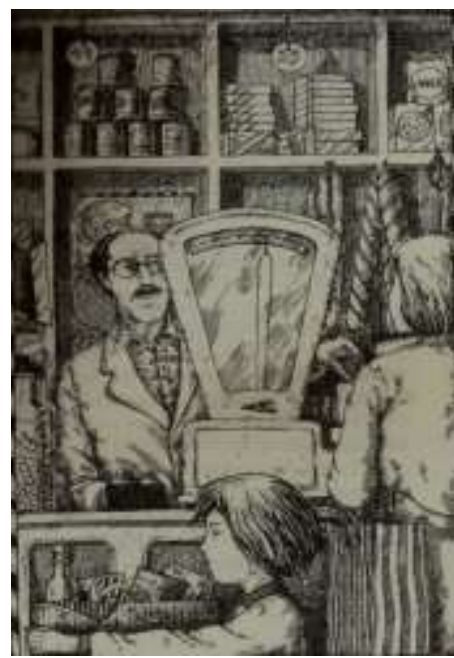

Fig. 9: Ilustración de Alfonso Ruano en Jeruso quiere ser gente, de Pilar Mateos (1981) mujeres practicando la costura en Cucho o en Un duende a rayas, una acción muy asociada al rol de la mujer que incluso se incluía en la formación de niñas hasta bien entrado el siglo XX (Peraita, 2017).

También nos sirven en esta línea las representaciones de personajes femeninos realizando otras labores domésticas, como las de los dibujos de Carme Solé Vendrell para Cepillo, donde la madre de Sala, el niño protagonista de la historia, aparece representada con una bandeja en la que porta diferentes elementos de una vajilla mientras atiende las tareas propias de la casa (Calders, 1981), o las de Jeruso quiere ser gente, de Pilar Mateos (1981), donde se representa a la mujer realizando la compra como una tarea más entre las obligaciones del hogar (Fig. 9). 


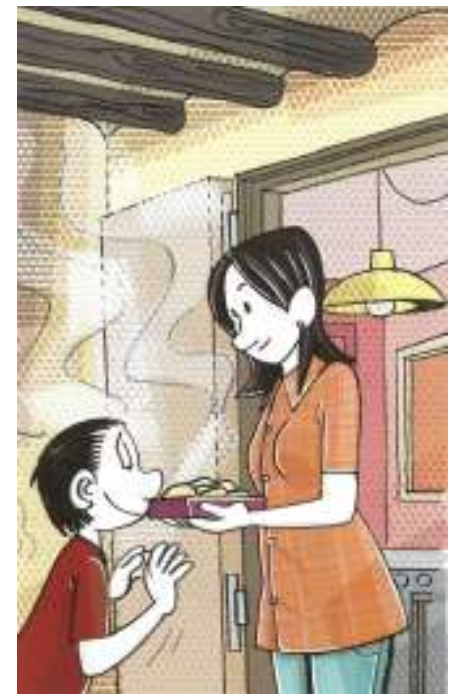

Fig. 10: Ilustración de

Agustín Comotto en

Veintisiete abuelos son demasiados, de Raquel

López (2014)
Esta imagen estereotipada sigue aún presente en obras de la última década que analizamos, como en Veintisiete abuelos son demasiados, de Raquel López, donde aparece la madre de Alex en el rol de cocinera (Fig. 10). Eso sí, se ilustra con una caracterización del personaje femenino que se corresponde con la que hemos documentado en el apartado anterior para obras de la década de 2010 y, además, se compensa con la aparición de otros personajes masculinos, como D. Francisco, con delantal y desempeñando esas mismas tareas de cocina (Fig. 11).

Hasta la última década que es objeto de nuestro estudio, lo normal es que los personajes masculinos, cuando aparecen realizando oficios o acciones con posible

sesgo de género, siempre llevan a cabo trabajos entendidos tradicionalmente como propios de los hombres. Incluso cuando se trata de acciones domésticas como el cocinado, si se desarrollan en un ámbito profesional, también aparecen asignadas a personajes masculinos (Fig. 12).

Esa tendencia empieza a superarse ya dentro del siglo XXI, cuando se aprecia la repercusión del aperturismo social y cultural que se inició algunas décadas atrás y que caracteriza al mundo contemporáneo. Dentro del ámbito de las tareas domésticas, hemos visto la materialización de este avance en la representación de D. Francisco en Veintisiete

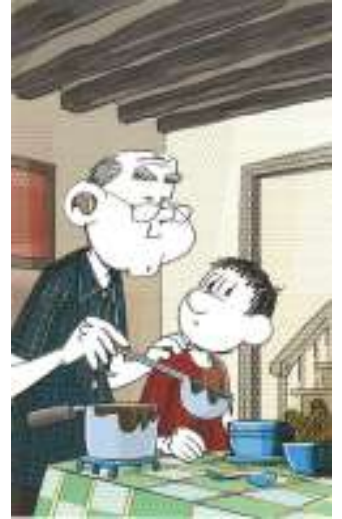

Fig. 11: Ilustración de Agustín Comotto en Veintisiete abuelos son demasiados, de Raquel

López (2014) abuelos son demasiados o en el álbum ilustrado La colección del abuelo, de Javier García Sobrino (2018), donde la ilustradora Bruna 
Valls representa personajes masculinos realizando acciones de cuidado del hogar (Fig. 13).

Otro ejemplo significativo en este nuevo modelo de

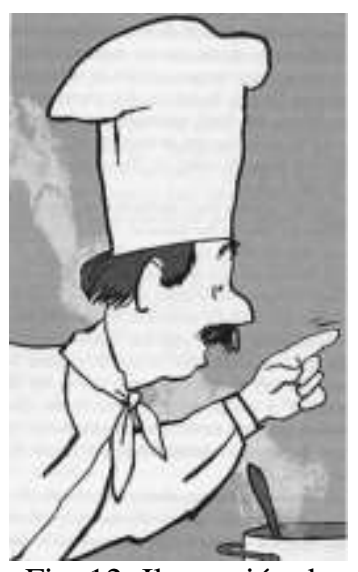

Fig. 12: Ilustración de Paola Escobar en Siete reporteros y un periódico de Pilar Lozano Carbayo (2005) representación de roles lo encontramos en el álbum La niña invisible, de Puño (Peña, 2018). La trama de esta obra se localiza en la prehistoria, un contexto en el que las mujeres aparecen desarrollando actividades como el curtido de pieles o el cocinado, mientras que las tareas de caza quedan reservadas para los hombres de la tribu. No obstante, el álbum cuenta precisamente la ruptura de esos cánones en el personaje de Trog, la niña invisible, que es capaz de imponerse a los patrones sociales para llevar a cabo tareas que, en principio, no le corresponden por su condición femenina y que terminan suponiendo una representación de la emancipación de la mujer (Fig. 14).

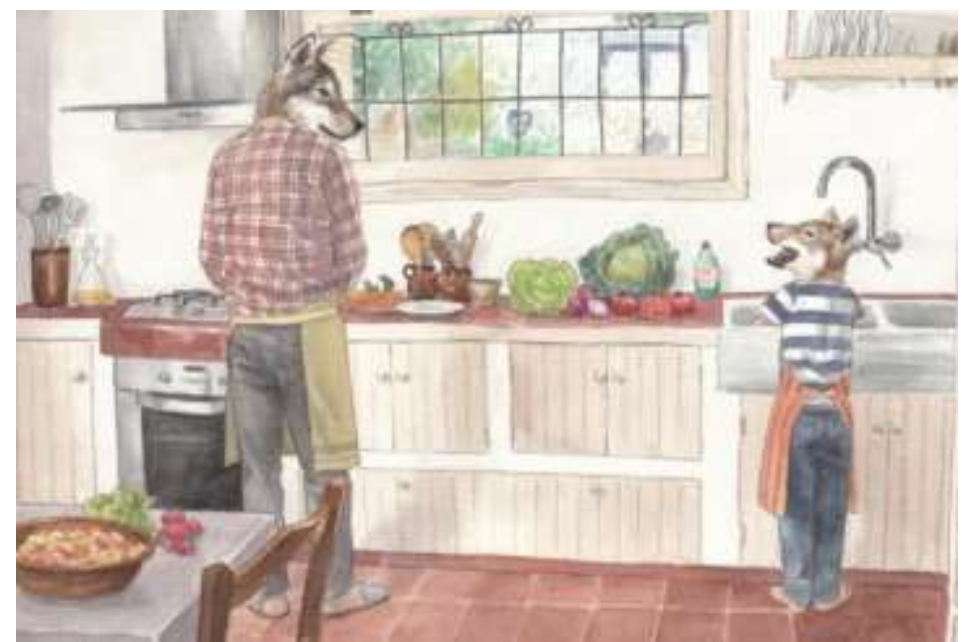

Fig. 13: Ilustración de Bruna Valls en La colección del abuelo, de Javier García Sobrino (2018) 


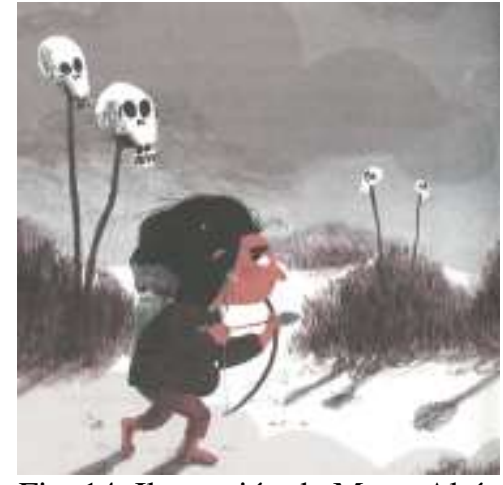

Fig. 14. Ilustración de Marta Altés

García en La niña invisible, de Puño (2018)

También se aprecia esa evolución en el campo de la igualdad en otros ámbitos, como en el cuidado de los hijos. Interesantes en este sentido son las aportaciones visuales de Andrés Guerrero para el texto Se vende mamá, de Care Santos (2009). En este caso, se cuenta la historia de Óscar, un niño que pone en venta a su mamá porque desde que nació Garbanzo, su hermano menor, cree que no lo quiere igual. En uno de los momentos de desahogo, el protagonista se cuestiona un planteamiento relacionado con el tema de la igualdad: “ $¿ Y$ dónde se ha visto un hombre de negocios cuidando de un bebé?" (Santos, 2009, p. 55). La evidente ironía del texto, que se refuerza en la ilustración, demuestra el cambio de parámetros en la catalogación de roles masculinos y femeninos dentro de la sociedad (Fig. 15).

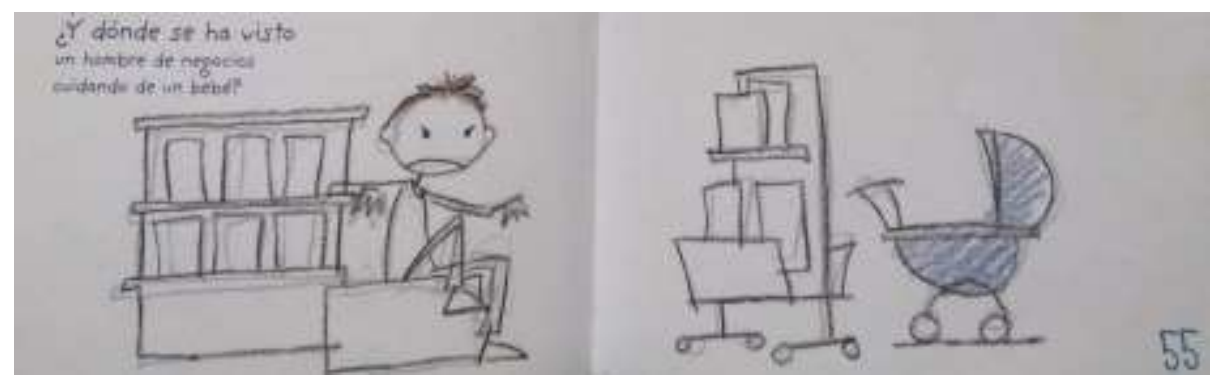

Fig. 15: Ilustración de Andrés Guerrero en Se vende mamá, de Care Santos (2009) 


\subsubsection{La localización como marca en la representación de los estereotipos de género}

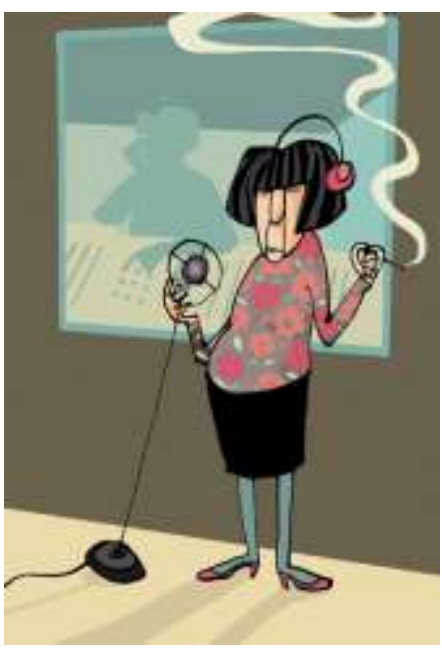

Fig. 16. Ilustración de Ximena Maier en Una terrible palabra de nueve letras, de Pedro Mañas (2012)

Tal y como quedó expuesto en el apartado dedicado a la metodología, el tercer parámetro que se analizará en este estudio se corresponde con la localización. En este sentido, como principio general se ha interpretado el paso del interior del hogar hacia nuevas localizaciones como un símbolo de emancipación e independencia (Cañamares-Torrijos y Moya-Guijarro, 2019).

En nuestro caso, puede observarse cómo en los títulos de las primeras décadas son frecuentes las representaciones de personajes femeninos dentro de espacios domésticos, como en los ejemplos ya vistos en Cucho (Fig. 1) o en Un duende a rayas (Fig. 2).

Frente a esta tendencia inicial, en las siguientes décadas se comprueba la localización de personajes femeninos en espacios interiores, aunque asociados al ámbito de lo público, que viene a simbolizar la mayor presencia social de la mujer en el desempeño de acciones que ya no dependen de lo doméstico. Algún ejemplo que puede ilustrar esta conclusión lo encontramos en Una terrible palabra de nueve letras, de Pedro Mañas, donde aparecen la directora del colegio al que asisten Amanda Banks y Billy Cooper, la profesora o la actriz Pamela Greenwood, que se representa en su trabajo para la Compañía de Juguetes de McMillan (Fig. 16).

Un último aspecto reseñable en este ámbito de la localización tiene que ver con el aumento de la presencia de la niña en juegos infantiles exteriores. En las ilustraciones clásicas se aprecia la segregación por sexos y la adjudicación de juegos tradicionalmente 
marcados para niños y para niñas, como puede verse en la ilustración de Antonio Tello en Cucho (1983) en la que aparece un grupo de niños jugando con la nieve (Fig. 17). Dentro del siglo XXI se concreta un avance ideológico en este aspecto que se materializa en la representación de personajes femeninos desarrollando acciones exteriores de juego consideradas tradicionalmente masculinas, por ejemplo, el fútbol, y en la tendencia a la representación de grupos infantiles mixtos. Sirven como ejemplo las ilustraciones de Veintisiete abuelos son demasiados, donde Agustín Comotto presenta a Álex, protagonista de la historia, junto a sus amigos y amigas corriendo entre árboles (Fig. 18), o las de Los escribidores de cartas, de Beatriz Osés (2019), donde son frecuentes las representaciones de la pandilla de amigos mixta en distintos escenarios exteriores. Esta imagen de la niña ocupando el espacio abierto y en convivencia con niños es una tendencia muy frecuente en la última literatura que permite suponer la superación de un estereotipo desfasado sobre el rol, las relaciones y los lugares apropiados para el ocio de niños y niñas.

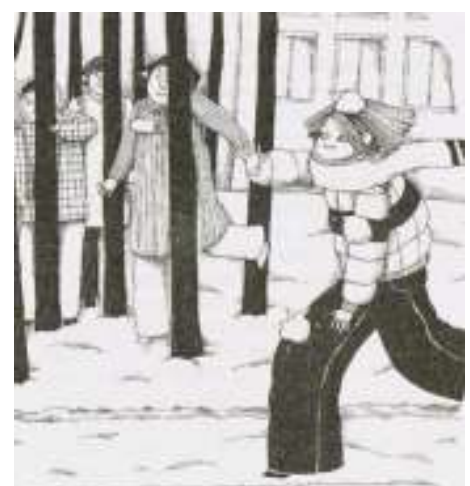

Fig. 17. Ilustración de Antonio Tello en Cucho, de José Luis Olaizola (1983)

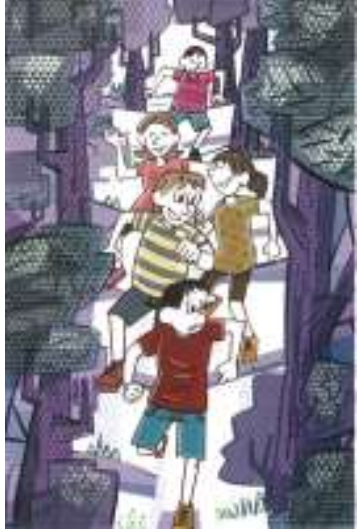

Fig. 18. Ilustración de Agustín Comotto en Veintisiete abuelos son demasiados, de Raquel López (2014) 


\section{Discusión y conclusiones}

El análisis de las ilustraciones en torno a la representación de roles y estereotipos de género evidencia cómo la imagen es un recurso con enorme potencial en el contexto de la coeducación. En este sentido, los resultados obtenidos demuestran un cambio en las tendencias generales en la ilustración que evidencia el avance social y cultural de las últimas décadas en el campo de la coeducación. De esta manera, el recurso visual se convierte en un medio para que el conocimiento de las funciones de los estereotipos suponga, en la línea de lo expuesto por Hayes (2013), más posibilidades de reflexión y pensamiento crítico.

Los resultados del análisis de las imágenes vinculadas a las 40 obras que han formado parte de este estudio muestran cómo en las primeras décadas se detectan representaciones estereotipadas en los tres parámetros analizados. En este sentido, cabe destacar cómo la caracterización de los personajes está muy marcada en los primeros ejemplos, pues se mantienen estereotipos heredados de las décadas centrales del siglo XX. Frente a la representación de una mujer que luce vestimentas vinculadas a su rol dentro del hogar (cocinera, costurera, cuidadora de hijos...), se detecta un aperturismo en los discursos visuales de género vinculados a la caracterización de los personajes en ilustraciones como la de Sabina y Riky, de Jesús Gabán, para el texto de Apareció en mi ventana, de Alfonso Gómez Cerdá (Fig. 5).

Los resultados del análisis evidencian, por otra parte, que esta evolución en la caracterización de los personajes queda aún más marcada en las ilustraciones de los textos del siglo XXI. Por un lado, prendas de vestir que tradicionalmente se han asociado al género masculino comienzan a formar parte de las ilustraciones de textos como Una terrible palabra de nueve letras, de Pedro Mañas (2012), en Veintisiete abuelos son demasiados, de Raquel López (2014) o en Cómo arreglar un libro mojado (2017), obra de Roberto Aliaga.

En este contexto de caracterización, se detecta también cómo en los últimos años ha sido común neutralizar el atuendo y, en consecuencia, desvincular las prendas de vestir del concepto de género. 
Por ejemplo, las ilustraciones de Mi vecino de abajo, de Daniel Nesquens, manifiestan ese cambio en la manera de caracterizar a los personajes, un recurso que contrasta con las representaciones más tradicionales en las que el atuendo aparece claramente vinculado al género.

El segundo elemento analizado, vinculado al estudio de las estrategias visuales utilizadas por los ilustradores en torno a la asociación de acciones y utensilios atendiendo al género, evidencia cómo en las obras de las últimas décadas se reducen las representaciones estereotipadas como consecuencia de los avances sociales en el ámbito de la igualdad. En este caso, frente a ilustraciones que en los años ochenta y noventa vincularon a los personajes con labores y utensilios propios del ámbito doméstico (véase, por ejemplo, Cepillo, de Pere Calders; Cucho, en su edición de 1983; o Un duende a rayas, de Margarita Puncel), en las últimas décadas se detecta un cambio en pro de la igualdad de género. El álbum ilustrado La colección del abuelo, de Javier García Sobrino (2018), o Se vende mamá, de Care Santos (2008), representan claramente la vinculación de ciertas acciones domésticas asociadas al rol de la mujer con las representaciones protagonizadas por hombres. De esta manera, se demuestra cómo acciones que hasta hace relativamente poco tiempo se solían asociar a la representación del colectivo femenino comienzan a formar parte de tareas desvinculadas del género en una visión moderna propia de la sociedad del siglo XXI.

Por último, cabe destacar los resultados obtenidos en torno al concepto de localización de la figura femenina en las ilustraciones de la muestra seleccionada. Frente a localizaciones de interior detectadas en las ilustraciones de los años ochenta, se observa en los últimos años la presencia de nuevas localizaciones que simbolizan la independencia de la mujer. En nuestro caso, hemos comprobado el aumento en los últimos años de personajes femenimos que salen al exterior para jugar o para desempeñar acciones de trabajo que representan una mayor presencia de la mujer en el ámbito social. Este cambio en la localización de la figura femenina queda patente también en la presencia de grupos mixtos en torno a acciones que salen fuera del contexto del hogar. 
En definitiva, los resultados del análisis planteado se pueden resumir en tres conclusiones: 1) En las obras de las primeras décadas que son objeto de estudio se detectan representaciones estereotipadas en los tres parámetros analizados; 2) en las ilustraciones de las últimas décadas se reducen las representaciones estereotipadas como consecuencia de los avances sociales en el ámbito de la igualdad; y 3) la imagen se presenta como un recurso de gran potencial para dar respuesta a procesos de coeducación, pues sus aportaciones son un claro testimonio de un proceso evolutivo en lo que a los roles y estereotipos de género se refiere.

\section{Referencias bibliográficas}

Arizpe, E., y Styles, M. (2004). Lectura de imágenes. Los niños interpretan textos visuales. México: Fondo de Cultura Económica.

Ashton, E. (1978). The efect of sex-role stereotyped picture books on the play behavior of three- and four-year-old children. Doctoral Dissertations. Recuperado de https://scholarworks.umass.edu/dissertations_1/3364.

Azevedo, F., Balça, Â., Selfa, M., y Zamith, J. (2015). A alteridade na Literatura Infantil contemporânea publicada no espaço ibérico: algumas vozes e configurações na construção do género. Elos: revista de literatura infantil e xuvenil, 2, 119-130. doi: https://doi.org/10.15304/elos.2.2569.

Aznar-Díaz, I., y Fernández-Martín, F. (2004). Adquisición de estereotipos sexuales a través de los medios de comunicación. Comunicar, 23, 121-123. doi: https://doi.org/10.3916/C23-2004-20

Boch, E., y Ferrer, V. (2003). Fragilidad y debilidad como elementos fundamentales del estereotipo tradicional femenino. Feminismo/s, 2, 139-152. doi: http://dx.doi.org/10.14198/fem.2003.2.09.

Borda, M. ${ }^{a}$ I. (2006). Cómo iniciar a la lectura. Málaga: Arguval.

Brugeilles, C., Cromer, I., y Cromer, S. (2002). Les représentations du masculin et du féminin dans les albums illustrés ou 
Comment la littérature enfantine contribue à élaborer le genre. Population, 57(2), 261-292. doi: https://doi.org/10.2307/1534872.

Campos, A., y González, M. ${ }^{a}$ Á. (2017). Importancia de las imágenes mentales en el pensamiento. Revista Mexicana de Investigación en Psicología, 2, 113-119.

Cañamares-Torrijos, C., y Moya-Guijarro, A. J. (2019). Análisis semiótico y multimodal de los escenarios de libros álbumes que retan estereotipos de género. Ocnos: Revista de Estudios sobre Lectura, 18(3), 59-70. doi: https://doi.org/10.18239/ocnos_2019.18.3.2127.

Castillo-Mayén M.a del R., y Montes-Berges, B. (2007). Escala de estereotipos de género actuales. Iniciación a la investigación, 2, 121. Recuperado de https://revistaselectronicas.ujaen.es/index.php/ininv/article/view/198/17 9.

Castillo-Mayén, M. ${ }^{\text {a }}$ del R., y Montes-Berges, B. (2014). Análisis de los estereotipos de género actuales. Anales de Psicología, 30(3), 1044-1060. Recuperado de https://www.redalyc.org/articulo.oa?id=167/16731690027.

Cerrillo, P., Larrañaga, E., y Yubero, S. (2002). Libros, lectores y mediadores. La formación de los hábitos lectores como proceso de aprendizaje. Cuenca: Universidad de Castilla-La Mancha.

Cervera, J. (1989). Literatura infantil: Los límites de la didáctica. Monteolivete, 6, 37-49.

Colomer, T. (2008). Introducción a la literatura infantil y juvenil. Madrid: Síntesis.

Crabb, P. B., y Bielawski, D. (1994). The social representation of material culture and gender in children's books. Sex Roles: A Journal of Research, 30(1-2), 69-79. doi: https://doi.org/10.1007/BF01420740

de Lemus, S. (2007). Estereotipos y prejuicio de género: Automatismo y modulación contextual. [Tesis Doctoral, Universidad de Granada]. Repositorio de tesis de la Universidad de Granada. https://digibug.ugr.es/handle/10481/1723.

Diekman, A. B., y Eagly, A. H. (2000). Stereotypes as dynamic constructs: Women and men of the past, present, and future. Personality and Social Psychology Bulletin, 26, 1171-1188. doi: https://doi.org/10.1177/0146167200262001. 
Diekman, A. B., Eagly, A. H., Mladinic, A., y Ferreira, M. C. (2005). Dynamic stereotypes about women and men in Latin America and the United States. Journal of Cross-Cultural Psychology, 36(2), 209-226. doi: https://doi.org/10.1177/0022022104272902.

Dovidio, J. F., Evans, N., y Tyler, R. B. (1986). Racial stereotypes: The contents of their cognitive representations. Journal of Experimental Social Psychology, 22(1), 22-37. doi: https://doi.org/10.1016/0022-1031(86)90039-9.

Fernández-Montesinos, A. (2016). Los estereotipos: definición y funciones.Iberic@l, Revue d'études ibériques et ibéro-américaines, 10, 53-63.

Fiske, S. T., y Stevens, L. E. (1993). What's so special about sex? Gender stereotyping and discrimination. En S. Oskamp y M. Costanzo (Eds.), Gender issues in contemporary society (pp. 173-196). Sage Publications, Inc.

García, E. (2005). La imaginación y el dibujo infantil. El test microgenético. Mexico D. F.: Tillas.

García-Prieto, I., y Arriazu-Muñoz, R. (2020). Estereotipos de género en educación infantil: un estudio de caso desde la perspectiva sociocultural. Zero-a-Seis, 22(41), 4-30. doi: https://doi.org/10.5007/1980-4512.2020v22n41p4.

García-Retamero, R., Müller. S. M., y López-Zafra, E. (2009). Sobre la maleabilidad de los estereotipos de género: influencia del tamaño de la población y el paso del tiempo en la percepción de hombres y mujeres. En J. Tous y Pallarès y J. M. Fabra Sopeña (Eds.), Actas del XI Congreso Nacional de Psicología Social, Vol. 2 (pp. 151155). Tarragona: Universitat Rovira i Virgili.

González, B. (1999). Los estereotipos como factor de socialización en el género. Comunicar, 12, 79-88. Recuperado de https://www.redalyc.org/articulo.oa?id=15801212.

Guimarães, R. (2013). Las funciones de la literatura infantil en la Educación. Revista Iberoamericana de Educación, 61(3), 1-10. doi: https://doi.org/10.35362/rie6131080

Guil-Bozal, A. (1998). El papel de los arquetipos en los actuales estereotipos sobre la mujer. Comunicar, 12, 95-100. doi: https://doi.org/10.3916/C12-1999-14. 
Hayes, N. (2013). Los estereotipos culturales como obstáculo para la convivencia en la escuela inclusiva. Tejuelo, 18, 101-114. Recuperado

de https://mascvuex.unex.es/revistas/index.php/tejuelo/article/view/2556.

Hamilton, M. C., Anderson, D., Broaddus, M., y Young, K. (2006). Gender stereotyping and under-representation of female characters in 200 popular children's picture books: a twenty-first century update. Sex Roles, 55, 757-765. doi: https://doi.org/10.1007/s11199-006-9128-6.

Heilman, M. E. (2001). Description and prescription: How gender stereotypes prevent women's ascent up the organizational ladder. Journal of Social Issues, 57(4), 657-674. doi: https://doi.org/10.1111/0022-4537.00234.

Hoffman, C., y Hurst, N. (1990). Gender stereotypes: Perception or rationalization? Journal of Personality and Social Psychology, 58, 197-208. doi: https://doi.org/10.1037/0022-3514.58.2.197.

Jost, J. T., y Hamilton, D. L. (2005). Stereotypes in our culture. En J. F. Dovidio, P. Glick y L. A. Rudman (Eds.), On the nature of prejudice: Fifty years after Allport (pp. 208-224). Oxford: Blackwell.

Lombardo, E., y León, M. (2014). Políticas de igualdad de género y sociales en España: origen, desarrollo y desmantelamiento en un contexto de crisis económica. Investigaciones Feministas, 5, 13-35. doi: https://doi.org/10.5209/rev_INFE.2014.v5.47986.

López-Sáez, M., Morales, J. F., y Lisbona, A. (2008). Evolution of gender stereotypes in Spain: Traits and roles. Spanish Journal of Psychology, 11(2), 609-617. doi: https://doi.org/10.1017/S1138741600004613.

López-Zafra, E., García-Retamero, R., Diekman, A., y Eagly, A. H. (2008). Dinámica de estereotipos de género y poder: un estudio transcultural. Revista de Psicología Social, 23(2), 213-219. doi: https://doi.org/10.1174/021347408784135788.

Martín-Macho, A., y Neira-Piñeiro, M. ${ }^{a}$ R. (2018). Diseño de una escala de valoración de álbumes ilustrados para educación infantil: una experiencia para la formación de futuros maestros como mediadores. Tejuelo, 27, 81-118. doi: https://10.17398/19888430.27.81. 
Martínez, N., y Torres, C. (2014). La Mochila Violeta. Guía de lectura infantil y juvenil no sexista y coeducativa. Granada: Delegación de Igualdad de Oportunidades y Juventud.

Masats, D., y Creus, T. (2006). Álbumes para abordar la interculturalidad y el género en las aulas de educación infantil. En E. Soriano, M. M. Osorio y A. J. González (Coords.). Interculturalidad y género (pp. 275-281). Almería: Universidad de Almería.

Morales, J. F., y López, M. (1993). Bases para la construcción de un sistema de indicadores sociales de estereotipia de género. Psicothema, 5, 123-132. Recuperado de https://reunido.uniovi.es/index.php/PST/article/view/7184/7048.

Moya, M. (2003). El análisis psicosocial del género. En J. F. Morales y C. Huici (Eds.), Estudios de Psicología Social (pp. 175-221). Madrid: UNED.

Moya, M., y Pérez, C. (1990). Nuevas perspectivas en el estudio de los estereotipos de género. En G. Musitu (Coord.), Psicología social y sociedad del bienestar (pp. 49-60). Barcelona: PPU.

Moya-Guijarro, A. J., y Cañamares-Torrijos, C. (2020). Libros álbum que desafían los estereotipos de género y el concepto de familia tradicional. Análisis semiótico y multimodal. Introducción. En A. J. Moya-Guijarro y C. Cañamares-Torrijos (Coords), Libros álbum que desafían los estereotipos de género y el concepto de familia tradicional. Análisis semiótico y multimodal (pp. 17-46). Cuenca: Universidad de Castilla-La Mancha.

Paivio, A., Rogers, T. B., y Smithe, P. C. (1968). Why are pictures easier to recall than words? Psychonomic Science, 11, 137-138.

Pastor, B. M. (2014). La literatura infantil como espacio mediador en la educación de género. Raído. Revista do Programa de Pós-Graduação em Letras da UFGD, 8(17), 87-104. Recuperado de https://ojs.ufgd.edu.br/index.php/Raido/article/view/3630.

Peraita, L. (2017). Cuando las familias vivían del sueldo del marido. $A B C, 10$ de julio. Recuperado de: https://cutt.ly/ZkQp3lh.

Peterson S. B., y Lach, M. A. (1990) Gender Stereotypes in Children's Books: their prevalence and influence on cognitive and affective development. Gender and Education, 2, 185-197. doi: https://doi.org/10.1080/0954025900020204. 
Pickering, M. (2007). Stereotyping and stereotypes. In G. Ritzer (Ed.), The Blackwell encyclopedia of sociology. Vol. X (pp. 47734778). Malden: Blackwell Publishing.

Pla, I., Adam, A., y Bernabéu, I. (2013). Estereotipos y prejuicios de género: factores determinantes en Salud Mental. Norte de salud mental, XI(46), 20-28. Recuperado de http://psiqu.com/2-34240.

Rodríguez, Y. (2016). La enseñanza y el aprendizaje de la coeducación en las aulas de educación infantil de la Región de Murcia. [Tesis doctoral, Universidad de Murcia]. Deposito digital de tesis doctorales de la Universidad de Murcia. https://digitum.um.es/digitum/handle/10201/50084.

Ros, E. (2012/2013). El cuento infantil como herramienta socializadora de género. Cuestiones pedagógicas, 22, 329-350. Recuperado de http://hdl.handle.net/11441/54424.

Salamanca, S. (2014). Coeducación, la erradicación de los estereotipos de género en la educación del siglo veintiuno. Iberoamérica Social: revista-red de estudios sociales, III, 84-91. Recuperado de https://iberoamericasocial.com/coeducacion-laerradicacion-de-los-estereotipos-de-genero-en-la-educacion-del-siglo$\mathrm{xxi} /$

Saneleuterio, E., y López, R. (2019). Contribución de la formación literaria a la educación integral: análisis del currículo básico de Educación Primaria. EA, Escuela Abierta, 22, 29-38. doi: https://doi.org/10.29257/EA22.2019.04.

Schon, I., y Berkin, S. C. (1996). Introducción a la literatura infantil y juvenil. Delaware: International Reading Association.

Steele, C. M. (1997). A threat in the air: How stereotypes shape intellectual identity and performance. American Psychologist, 52(6), 613-629. doi: https://doi.org/10.1037/0003-066X.52.6.613.

Terrón, M. ${ }^{a}$ T., y Cobano-Delgado, V. (2008). El papel de la mujer en las ilustraciones de los libros de texto de Educación Primaria. Foro de Educación, 10, 385-400. Recuperado de https://www.forodeeducacion.com/ojs/index.php/fde/article/view/166.

Tomé, A. (2002). El estado de la cuestión: la coeducación en la etapa de infantil y primaria. En M. ${ }^{\mathrm{a}}$ Luisa Abad (Coord.). Género y educación. La escuela coeducativa (pp. 49-56). Barcelona: Graó. 
Turin, A. (1989). Hermosas, cariñosas y pacientes. CLIJ: Cuadernos de literatura infantil y juvenil, 2(11), 24-27. Copia digital. España: Ministerio de Cultura y Deporte. Subdirección General de Cooperación Bibliotecaria. Recuperado de https://prensahistorica.mcu.es/es/consulta/registro.do?id=1010825.

Turin, A. (1995). Los cuentos siguen contando. Algunas reflexiones sobre los estereotipos. Madrid: Horas y Horas.

Turin, A. (1996). ¡Atención! Álbum ilustrado. Peonza: Revista de literatura infantil $y$ juvenil, 39, 23-26. Recuperado de https://cutt.ly/dmVtWm6.

Turin, A. (2002). Un sillón, un delantal, un niño = una familia. Boletín de la Institución Libre de Enseñanza, 42-43, 111-130.

Unger, G. F. (1989). Formación y desarrollo de la identidad sexual en la infancia y adolescencia. Nueva York: Baywood.

Vega, S. (2012). Coeducación en la escuela infantil. Publicidad y género. En I. Vizcaíno, y A. Blasco (Coords.), Hablemos de educación infantil: orientaciones y recursos (0-6 años) (p. 13). Madrid: Wolters Kluwer Education.

Velasco, S. (2009). Sexos, género y salud. Teoría y métodos para la práctica clínica y programas de salud. Madrid: Minerva.

Vignera, M. E. (2018). El sexo y la identidad de género y su relación con variables psicoeducativas en estudiantes universitarios. [Tesis Doctoral, Universidad de Alicante]. Repositorio Institucional de la Universidad de Alicante. http://hdl.handle.net/10045/103755.

Weitzman, L., Eifler, D., Hokada, E., y Ross, C. (1972). SexRole Socialization in Picture Books for preschool Children. American Journal of Sociology, 77, 1125-1150. doi: https://doi.org/10.1086/225261. 


\section{Anexo. Relación de obras analizadas}

Aliaga, R. (2017). Cómo arreglar un libro mojado. Ilustraciones de Clara Soriano. Madrid: SM.

Almena, F. (1983). Un solo de clarinete. Ilustraciones de Margarita Puncel. Madrid: SM.

Alonso, A. y Pelegrín, J. (2008). El secreto de If. (9. ${ }^{\text {a }}$ ed.). Ilustraciones de Marcelo Pérez. Madrid: SM.

Baquedano, L. (1986). Fantasmas de día. (20. ${ }^{\text {a }}$ ed.). Ilustraciones de Tino Gatagán. Madrid: SM.

Bordons, P. (2004). Sombra. (7. a ed.). Ilustraciones de Alfonso Ruano. Madrid: SM.

Calders, P. (1981). Cepillo. Ilustraciones de Carme Solé Vendrell. Pontevedra: Kalandraka.

Campos, Ll. (2014). El tesoro de Barracuda. Ilustraciones de Júlia Sardà. Madrid: SM.

Cañizo, J. A. del (1997). ¡Cañalla, traidor, morirás! Ilustraciones de Tino Gatagán. Madrid: SM.

Fernández, D. (2014). Luces en el canal. (4. ${ }^{\text {a }}$ ed.). Ilustraciones de Puño. Madrid: SM.

Ferrari, A. (2008). El complot de las flores. (7. ${ }^{\text {a }}$ ed.). Ilustraciones de Beatriz Castro. Madrid: SM.

Frabetti, C. (2007). Calvina. Ilustraciones de Miguel Navia. Madrid: SM.

Frabetti. C. (2020). ¿Quién quieres ser? Ilustraciones de Joan Casaramona. Madrid: SM.

Gallego, L. (1999). Finis Mundi. Ilustraciones de Pablo Torrecilla. Madrid: SM.

Gallego, L. (2015). La leyenda del rey errante. (24. ${ }^{\mathrm{a}}$ ed.). Ilustraciones de Daniel Montero. Madrid: SM.

García, J. (2018). La colección del abuelo. Ilustraciones de Bruna Valls. Zaragoza: Edelvives.

Gisbert, J. M. (2002). El mensaje de los pájaros. Ilustraciones de Fabiola Correas. Madrid: SM.

Gómez, R. (2006). Ojo de nube. Ilustraciones de Jesús Gabán. Madrid: SM. 
Gómez, A. (1990). Apareció en mi ventana. Ilustraciones de Jesús Gabán. Madrid: SM.

González, C. (2014). El secreto del huevo azul. (6. ${ }^{\mathrm{a}}$ ed.). Ilustraciones de Tomás Hijo. Madrid: SM.

Lalana, F. (1992). Silvia y la máquina Qué. Ilustraciones de Gonzalo Izquierdo. Madrid: SM.

Lindo, E. (1997). Los trapos sucios. Manolito gafotas. Ilustraciones de Emilio Urberuaga. Madrid: Alfaguara.

López, R. (2014). Veintisiete abuelos son demasiados. Ilustraciones de Agustín Comotto. Madrid: Anaya.

Lozano, P. (2005). Siete reporteros y un periódico. Ilustraciones de Juan Ramón Alonso. Madrid: SM.

Mañas, P. (2015). La vida secreta de Rebecca Paradise. Ilustraciones de Bea Tormo. Madrid: SM.

Mañas, P. (2012). Una terrible palabra de nueve letras. Ilustraciones de Ximena Maier. Madrid: Anaya.

Mateos, P. (1981). Jeruso quiere ser gente. Ilustraciones de Alfonso Ruano. Madrid: SM.

Merino, J. A. (1992). El “Celeste”. Ilustraciones de Toño Benavides. Madrid: SM.

Moleón, M. A. (2002). El rey Arturo cabalga de nuevo, más o menos (12. 'ed.). Ilustraciones de Tino Gatagán. Madrid: SM.

Moure, G. (1997). Lili, Libertad. (35. a ed.). Ilustraciones de Srta. M. Madrid: SM.

Nesquens, D. (2011). Mi vecino de abajo. Ilustraciones de Fran Collado. Madrid: SM.

Olaizola, J. L. (1983). Cucho. (1. a ed.). Ilustraciones de Antonio Tello. Madrid: SM.

Olaizola, J. L. (2018). Cucho. (40. ${ }^{\mathrm{a}}$ ed.). Ilustraciones de Paula Blumen. Madrid: SM.

Osés, B. (2019). Los escribidores de cartas. Ilustraciones de Kike Ibáñez. Madrid: SM.

Peña, D. (2018). La niña invisible. Ilustraciones de Marta Altés. Madrid: SM.

Puerto, C. (1997). Las alas de la pantera. (4. ${ }^{\mathrm{a}}$ ed.). Ilustraciones de Alfonso Ruano. Madrid: SM. 
Puncel, M. (1984). Un duende a rayas. (3. a ed.). Ilustraciones de Margarita Puncel. Madrid: SM.

Santiago, R. (2016). Los protectores. Ilustraciones de Paula Blumen. Madrid: SM.

Santos, C. (2009). Se vende mamá. Ilustraciones de Andrés Guerrero. Madrid: SM.

Sierra, J. (2010). Historia de un segundo. (10. ${ }^{\mathrm{a}}$ ed.). Ilustraciones de Carlos Velázquez. Madrid: SM.

Vaccarini, F. (2006). La noche del meteorito. Ilustraciones del Vladimiro Merino. Buenos Aires: SM. 
Tejuelo, $\mathrm{n}^{\circ} 34$ (2021), págs. 15-48. Análisis diacrónico de los roles y estereotipos de género de las ilustraciones... 